\title{
Beyond Models: Developing a University Strategy for Online Instruction
}

\author{
Ian C. Reid \\ Coordinator: Online Services \\ Flexible Learning Centre \\ Holbrooks Road \\ Underdale, South Australia, 5032 \\ University of South Australia \\ Phone: +61 883027074 \\ FAX: +61883026767 \\ E-mail: ian.reid@unisa.edu.au
}

\begin{abstract}
Universities are being pressured from a range of forces to move into delivery of courses via online methods. While the literature is replete with promises for the use of information technology (IT) in the teaching and learning environment of higher education institutions, it is difficult for those institutions to take a strategic and informed approach to its implementation. This paper details the difficulties that can arise in selecting and implementing online delivery solutions and seeks to survey various approaches that universities can take to address these difficulties from an organisational perspective. Key questions are then proposed that must be answered if academic managers are to be strategic in their selection of IT resources for teaching and learning, in order to best add value to their teaching and learning environment by providing access for students to asynchronous learning networks. Amongst the critical issues that need to be addressed are scalability, interoperability, consistency and flexibility. A progress report of an implementation of a strategic institution-wide approach to online delivery at the University of South Australia that addresses these key questions is then presented.
\end{abstract}

\section{KEYWORDS}

Asynchronous learning, Information technology, Online instruction

\section{INTRODUCTION}

Deciding how to develop online delivery mechanisms at an institutional level is not an easy task. This paper contends that the best approach is for each institution to address a number of key criteria in the context of their own previous developments in the use of information technology (IT), the resources they have at their disposal and the strategic directions of the institution. In order to illustrate the application of these criteria a latter section describes one institution's response, namely UniSAnet, the online teaching and learning environment at the University of South Australia.

\section{THE INSTITUTIONAL CONTEXT}

The literature is replete with advice and warnings for the use of information technology in the teaching and learning environment of higher education institutions [1], [2], [3], [4]. At the institutional level the introduction of new technologies for online delivery has the capacity to bring changes which resist compartmentalisation - in fact new information technologies bring a change of institutional culture. This means that changes in the area of information technology require analysis and planning for 
implementation in areas that reach beyond the technical realm. Indeed, such changes involve (1) systems issues--the technical and human infrastructure required and the institution's capacity to provide it, (2) producer issues--the ways in which knowledge can be constructed in online learning environments and (3) user issues--the ease of access to, and connections between, online materials, in addition to the quality of those materials.

There are a number of reasons why these system, producer and user issues provide significant challenges for bringing about changes to an online learning environment. Some of these are now considered.

Firstly, there are issues relating to the rate of technical change. Technical tools and services change so rapidly that the traditionally slow organisational processes of universities cannot keep up. The hardware and software solutions available are changing and proliferating so fast that universities cannot hope to fund purchases of the latest products. This creates significant problems for institutions which aim to link directly with the practices of graduate employers and attending to issues of lifelong education, since students and their employers often require leading edge technologies to be taught to assist their competitive advantage in the employment and business marketplaces, respectively.

Secondly, issues of skill development need to be addressed. The level and diversity of the IT skills and experiences of the student body are rapidly outstripping those of most academics. The need for academics to keep up to date with their discipline itself is increased by the impact of IT, which can make it more problematic for them to remain up to date with learning technologies. On the other hand in some other areas, technological skills enable both staff and students to achieve goals (such as information retrieval and analysis) more efficiently than was possible in the past.

Thirdly, issues of communication are important. It is becoming increasingly difficult for IT specialists and managers of higher education institutions to communicate effectively with each other. The cultures of the technologist and the manager are diverging at an ever-increasing rate. As technologists deal with increasingly esoteric technologies and with interconnected global networks rather than merely institutionbased systems, and as managers become more engrossed with management systems, competitive pressures and the bottom line, the space for each group to communicate is narrowing dramatically. The technologist's informal networking can appear to be 'playing' to the manager, while the manager's focus on outcomes can appear to be a straightjacket to the technologist. This is occurring at a time when the future of universities undoubtedly relies on a close interdependence between the technologist and the manager.

The fourth set of reasons institutions are having difficulty with IT strategy involves technical expertise. Universities are now increasingly unable to keep staff with cutting edge technology skills. It is becoming difficult to pay the sort of salaries available to technologists in industry, and it is also difficult to provide the sort of leading edge environment in which these specialists need to work, as they once were able to do. Whereas in the past leading edge IT research and development was almost the sole domain of universities, the places with the funding, and the ideas, are now increasingly hardware and software companies. Thus universities are experiencing a drain of talent in the application of IT to teaching and learning.

Finally, the nature of the computer industry causes difficulties. The strategies of IT companies are often counter to the institutions' best interests. In a low margin industry companies require high volumes and will sell products that are customisations of business products rather than develop products specifically intended for the university environment. Also, in order to develop a long-term relationship with a university, these companies frequently use the traditional entrepreneurial approaches to lock in a customer to using its product exclusively. One such approach is to sell at a loss in the early stages of a relationship, while making the university customer reliant on its product and thus ensuring future sales at a higher 
price. The sale of online teaching software packages is a prime example. The vendor of these packages often convinces academics to lock up their intellectual property in a proprietary system, and then requires the payment of a license fee for the privilege to access that material, with the academic then at the mercy of future price rises in the fee.

Notwithstanding these difficulties, universities are presented with the need to develop organisational approaches that will facilitate the changes needed to implement online instruction. These approaches are now considered, with the following aim: to find the most efficient and effective way to bring the benefits of asynchronous learning networks to as many students as possible.

\section{A. Some Organisational Models}

A number of organisational frameworks for the consideration of online learning interventions have been proposed. Two such models, those of Bates from Canada and Yetton from Australia, are now considered. Bates focuses on institutional strategies, while Yetton uses institutional types as organising principles

Bates [5] develops an ACTIONS model (Access, Costs, Teaching functions, Interaction and userfriendliness, Organisational issues, Novelty, Speed of course development / adaptation) for selecting technologies and translates these choices in his 1997 paper [6] into 12 organisational strategies for change. These are:

1. A vision for teaching and learning

2. Funding reallocation

3. Strategies for inclusion

4. Technology infrastructure

5. People infrastructure

6. Student computer access

7. New teaching models

8. Faculty agreements and training

9. Project management

10. New organisational structures

11. Collaboration and consortia

12. Research and evaluation

Bates claims that the timing and coordination of these 12 strategies are imperative if technological changes in teaching and learning are to be successful. He accepts that the type of institution will inevitably affect the emphasis placed on each of these strategies, and that the integration of these strategies could take ten years to achieve. It could be argued that the virtual environment described by Goldman, Goldman and Nagel [7] in which universities find themselves, requires them to move more rapidly than this time scale.

Yetton [8] has identified three major approaches to the introduction of technology in the delivery and administration of higher education in Australia. The three models are compared following the technique developed by Hicks and George [9] in their analysis of strategic approaches to supporting learners. The factors compared are the online strategy, product selection strategy, the aims supported, the competitive edge provided, and the role of professional development, its advantages and its disadvantages.

Model 1:

IT (Information Technology) is used to enrich its elite learning community. This model, based on maintaining the established base while funding independent new ventures, creates a number of small entrepreneurial ventures based on unique and different competencies. Successful ventures grow, while 'feeding' the established university campus with their innovations in teaching, learning and research. The 
ventures have the ability to select expertise with few constraints, including terms and conditions of employment. This attracts high status academic risk takers and innovators. The administrative IT system will be flexible and user-friendly ([8], p. 4).

The online strategy employed by this form of university basically comprises a cottage industry, where specialist online products are developed for a particular market. The particular aims of the academic sponsoring (and often constructing) the application are of prime importance, and total control of intellectual property is assured. The difficulties of this approach are that it can be difficult to translate these specialist products to a wider audience, thus making it difficult for the approach to contribute to the institution's competitive position, and the result is a costly venture. Professional development has no place within this model, other than that required by individuals to author particular products.

Model 2:

IT supports the success of semi-autonomous faculties. The devolved powerful faculties, enabled by a powerful central IT infrastructure, each have different competencies and strategic foci. This form is more complex to manage given its scale, but relies on the focused innovation and particular competencies of its academic divisions to manage and limit that complexity. Each division would have its own IT support, and to some extent develop its own appropriate set of technologies, management processes and skills and roles, which focus on the division's core competencies in particular areas of applied research and teaching ([8], p. 4).

Within this approach, each autonomous division would select a single product for its online delivery. This is often an adaptation of a business-related product. This product is then mandated for use across the division, and only those academics or faculties with funds gain support from the initiative. This provides some competitive advantage for those wealthy discipline areas and has low startup costs, but ongoing support costs. The only professional support required is usually of a technical nature. It can be difficult to expand this approach to the entire University, due to the inefficiencies of different products being selected by different autonomous Divisions. In addition intellectual property is often locked up in a proprietary system for which annual fees need to be paid in order for it to be used.

Model 3:

IT is central to and critically underpins the strategic agenda. A new 'subsidiary' delivers IT-based teaching and learning, undertaking its innovative IT-based development in a separate, centrally resourced unit, and building new core competencies. IT enabled teaching and learning, designed to deliver quality and reliability to a large number of students, is the key driver in this model. In such a "greenfield" site, highly skilled experts can be selected as required, with a focus on the motivation and ability to work in multifunctional teams. Administration will be primarily management based ([8], p. 4).

This form of institution applies a mass production approach to online delivery. The university selects a particular online delivery product and supports all academic staff to develop using the product, requiring high levels of student and staff support. By supporting the institution's strategy in teaching and learning, it can assist the institutions competitive position, but requires high resource commitment and considerable pedagogical input is needed. It provides a low startup cost and can produce materials that have a consistent 'look and feel'. However the approach can involve the loss of control of intellectual property, as in model 2 , and the single product model can reduce flexibility. 
The comparisons of Yetton's three models are summarised in Table 1.

\begin{tabular}{|c|c|c|c|}
\hline & Model 1 & Model 2 & Model 3 \\
\hline Online strategy & Cottage industry & $\begin{array}{l}\text { Single product } \\
\text { approach }\end{array}$ & $\begin{array}{l}\text { Mass production } \\
\text { approach }\end{array}$ \\
\hline $\begin{array}{l}\text { Product selection } \\
\text { strategy }\end{array}$ & $\begin{array}{l}\text { Specialist products } \\
\text { developed }\end{array}$ & $\begin{array}{l}\text { Individual academics or } \\
\text { divisions select and use } \\
\text { a particular product }\end{array}$ & $\begin{array}{l}\text { The University selects a } \\
\text { particular online } \\
\text { delivery product and } \\
\text { supports staff to } \\
\text { develop using the } \\
\text { product }\end{array}$ \\
\hline $\begin{array}{l}\text { Whose aims are } \\
\text { supported }\end{array}$ & $\begin{array}{l}\text { Individual development } \\
\text { for academic }\end{array}$ & $\begin{array}{l}\text { Supports academics or } \\
\text { faculties with funds }\end{array}$ & $\begin{array}{l}\text { Supports the } \\
\text { institution's strategy }\end{array}$ \\
\hline $\begin{array}{l}\text { Support for } \\
\text { competitive edge }\end{array}$ & low & $\begin{array}{l}\text { medium for particular } \\
\text { discipline areas }\end{array}$ & $\begin{array}{l}\text { Requires high resource } \\
\text { commitment }\end{array}$ \\
\hline $\begin{array}{l}\text { Role of } \\
\text { Professional } \\
\text { Development }\end{array}$ & none & $\begin{array}{l}\text { Technical support with } \\
\text { little pedagogical input }\end{array}$ & high \\
\hline Advantages & Control over IP & Low startup cost & $\begin{array}{l}\text { Institution-wide } \\
\text { strategy with } \\
\text { considerable } \\
\text { pedagogical input } \\
\text { required } \\
\text { Low startup cost } \\
\text { Consistent look and } \\
\text { feel }\end{array}$ \\
\hline Disadvantages & $\begin{array}{l}\text { Costly } \\
\text { Not scalable }\end{array}$ & $\begin{array}{l}\text { Blackbox problem } \\
\text { Not scalable } \\
\text { Inefficient }\end{array}$ & $\begin{array}{l}\text { Not flexible } \\
\text { High staff development } \\
\text { costs } \\
\text { Loss of control of IP }\end{array}$ \\
\hline
\end{tabular}

Table 1. Online strategies compared.

All of Yetton's models of university organisation with respect to IT integration have disadvantages when considered in the light of the economic and technical pressures presented by Goldman, Goldman and Nagel, nor do they attend to the issues brought to universities by post-Fordism [10]. Distance education has been critiqued as being a manifestation of "instructional industrialism," [11] in that its processes come out of mass production methods, as developed by Ford for industrial manufacturing. For example, these "Fordist" principles have been shown by King [12] to be exemplified in the development of the Open Learning Agency in Australia. "Post-Fordism" refers to post-industrial or post-modern approaches which encompass concepts such as "open learning," "flexible learning" or "virtual campus" which by their very nature resist mass production methods of instructional delivery. Post-Fordism is a concept that allows distance education to be understood in terms of late-modernity [13] and describes production and consumption processes which are increasingly fragmented, decentralised and mediated by networks such as asynchronous learning networks. Such post-Fordist mechanisms allow teachers and learners to be dispersed over time and space, yet continue to interact via these networks.

Technical developments which allow highly scalable and interoperable solutions to the development of online learning resources, in conjunction with the capacity to respond to economic pressures to compete on a global scale with flexible management practises require a new advance on model 3 to be established - a mass customisation model. Such a model involves the establishment of templates and frameworks developed inhouse to retain control over intellectual property and the manner in which it is presented. There must be institutional agreement on a strategy that provides both basic tools to the individual 
academic with minimal technical training and a flexible structure within which highly innovative and experimental ventures can be mounted.

If one agrees with Bates [6] that "The new technologies will be exploited best by those that lend themselves to the new post-Fordist environment" then it is better to propose a range of criteria which should be met by any proposal for the development of online resources than to prescribe fixed structures and processes for IT implementation. These criteria should be driven by the sorts of business, IT and organisational principles discussed above, but should be flexible enough that Universities can respond to them in dynamic and flexible ways. The responses to these criteria can then change rapidly over time depending on the economic, social and technical environment. The criteria developed here have their genesis from the integration of the organisational models discussed above. They prescribe questions to be asked rather than simple solutions. The solutions within this framework will change rapidly depending on the very economic, social and technical exigencies that Universities need to address in dealing with online strategy. They are now discussed in some detail.

\section{B. Addressing System Issues}

A successful online learning system should be cost efficient and produce the maximum functionality possible. It will make the best possible use of the university's academic resources, while protecting its intellectual property.

\section{Extensibility and Interoperability}

An extensible online delivery system provides the ability to address the needs of the entire university. It allows all students to access online learning materials, as necessary, for all subjects they are studying, as determined by their learning needs, and all teachers to author learning materials. Interoperable systems move beyond the 'black box' model to open systems that allow users to access data for a range of purposes so that users can access information and construct knowledge from a variety of sources within the consistent learning framework of the online system. Universities make considerable investments in corporate information technology systems, and online delivery initiatives should ideally use or at least interface directly with these systems wherever possible in order to add value to these investments and to provide extensibility, interoperability and thus efficient use of resources.

Extensibility and interoperability are desirable in order for there to be a consistent online dimension for all subjects and courses in the university, and so that all relevant staff are able to customise these online materials with minimal lead time. This implies that that the systems used should be integrated with corporate information management systems to provide both efficiency and flexibility in preparation for future developments in delivering materials online, with respect to both client and server applications.

\section{A Critical Choice: Functionality Vs Interoperability and Extensibility}

In the design of an online delivery system, decisions need to be made about functionality on the one hand and interoperability and extensibility on the other. If one considers the online learner in isolation, functionality wins this choice every time. Every learner wants to be able to do as much as possible in the online environment. Aggregating these individual choices into an online learning system, however, is untenable. It is not possible to develop a system that provides total freedom for each individual user. Nor indeed is this desirable from a consistency or complexity perspective, as described below. In addition the provision of online resources for all students, for all subjects, is an inclusive approach to the provision of learning materials.

Hence products need to be selected or developed on the basis of the questions in the following priority order:

Priority 1: Does the system interoperate with all corporate systems?

Priority 2: Will the system extend to use by the university as a whole? 
Priority 3: Is there maximum functionality in the system?

This is a critical shift in the traditional view of educational software, where functionality has in the past been the major determinant for product selection.

\section{Security}

The protection of intellectual property requires that student and staff access to online materials have appropriate security applied. Decisions need to be made about:

- The method for authentication

- Ways in which logons for all subjects and all systems can be coordinated

- The nature of helpdesk support needed by students

This will facilitate student and staff use of materials by minimising the difficulties in accessing online materials, and allow the university to address mission-critical applications such as online enrolment and fees payment.

\section{Addressing Producer Issues}

In delivering online learning resources, knowledge is constructed by the production of learning and teaching resources. These resources include text, graphical and audio-visual resources, interactive online discussions, links to external sites on the internet and interactive assessment tasks. The producers of these resources can be teachers, students, support staff or some combination of these. How these producers use an online system is of prime importance.

\section{Role of Subject Developers}

Subject developers author the content and processes of learning. In the university setting, academic staff is responsible for the development of subject materials including those placed online, but information technology support staff is crucial to the success of online delivery. The university needs to decide how these two skill sets will interface in order to achieve efficient subject development. While control over content will remain with the academic responsible for the teaching of the subject, decisions need to be made about:

- Processes by which courses and subjects are identified for particular online developments

- Processes by which staff are identified and supported in their involvement in online delivery

- Ways in which subject developers are given professional and technical support

The focus should be on allowing academic staff to be able to maintain online teaching materials with sustainable technical and professional support.

\section{Role of Application Developers}

Application developers author and use the computer programs required to create online systems. Universities have a range of expertise at their disposal for the development of online applications, notably from information technology specialists, academic support units, the Library, academic and general staff located in academic units and external providers. In order to produce system components that are interoperable and extensible, developers need to comply with certain standards. In the context of curriculum developments, this means that the online system must provide a consistent vehicle for these producers to develop resources. Standard tools for building online delivery systems need to be agreed in the areas of:

- The creation of online resources on the Worldwide Web via HTML authoring

- The storage and manipulation of those resources usually by the development of content databases

- The connections between the online resources and the storage mechanisms, by linkage of databases to web pages

- The provision of interactivity between people via messaging 
- The provision of interactivity between people and resources via online tools such as quizzes and search engines

- The standards to which authoring work must comply

- The means by which online materials are made available on the internet, via web server software

\section{Addressing User Issues}

The users of an online learning system are diverse and unpredictable. They come from a range of backgrounds, use online resources for a range of purposes and will access materials from a range of locations, in a variety of sequences and at any time. This makes the notion of controlling users' use of materials more problematic, and increases the need for consistent, simple and easy to read materials with an engaging look and feel. Whilst users can be teachers, learners, administrators, technical staff or a range of other possible stakeholders, learners are focussed upon here.

\section{Access to Materials}

Among the access needs to be considered are the software and networking required and the temporal availability of materials. Hence the software needed by students to access materials, including the version, needs to be determined. The lowest version of web browser software possible should be prescribed, to improve accessibility, and all versions equal or above should be tested for consistency.

Since students may wish to access materials independent of time and space, in an international context, decisions need to be made about:

- The provision of access to the system from outside the university via its own dialup facility or Internet Service Providers. In this latter case the nature of the relationship between Internet Service Providers and the university need to be determined

- The use of intranet sites that are accessible only within university campuses via its internal network

- the appropriate assigning of write and read access to materials so that the institution can control the production and distribution of its intellectual property

The aim should be to allow students to have seamless access to materials which they need to carry out their studies and developers to be able to author materials in a timely and flexible fashion. The system should be available on a 24-hour, 7-day-per-week basis.

Interactivity is a key requirement for all learning, including online learning. The degree to which interactive materials will be synchronous or asynchronous can limit user access. Asynchronous interactions have the advantage of being accessible at different times, while synchronous interactions are immediate and ephemeral.

\section{Usability}

The university's online learning environment should aim to avoid the need for major training for entrylevel developments, while providing support for users as their skills develop in using the system. This applies equally for teachers and students. The use of standard hardware and software, with consistent, simple to use authoring and learning tools diminishes the complexity for staff and students teaching and learning online, thus reducing the training required.

The maintenance of software, hardware and the content of the learning materials should be as simple and consistent across the institution as possible and the cognitive load caused by switching from one environment to another is thus reduced. It should undergo rigorous user testing and improvement. 


\section{ONE INSTITUTION'S RESPONSE: UNISANET}

These criteria, if met, enable the development of a mass-customisation model for the development of online teaching and learning environments that is both sustainable by an institution's infrastructure and flexible enough to adapt to the emerging technical, social and economic environment. This strategic approach has been exemplified in the UniSAnet development of an online environment at the University of South Australia. UniSAnet comprises the linking of both existing corporate databases and purposebuilt [custom] data stores linked to web pages. These can be operated upon via standard web interfaces via web forms and wizards thus providing for full extensibility and interoperability. For example information about subjects is stored in one database and is utilised in the production of a range of print and online products. Whilst this reduces, to a small extent, the degree of functionality provided for, the strategic decision has been made that 'boutique' types of products are best provided for in specialist contexts which can then be linked directly to from the standard interfaces described here.

UniSAnet concentrates on a functionality that can be accessed via a standard browser interface without the need for the installation by the user of specialist software, particularly plugins. This platform, whilst including text-based materials, online discussions and interactive quizzes, can then be used to extend the richness of the resource base for teaching and learning by increasing the use of a range of multimedia forms. It provides a simple and consistent user interface for all of the university's online offerings.

UniSAnet is being implemented in stages. Underlying these is the strategic intent to:

- Establish immediately an online presence for every staff member, subject and course in the university. Students will have access via a standard browser to a simple and straightforward set of teaching and learning resources without requiring all academic staff to develop new skills. This provides a highly flexible authoring environment that provides a reasonable level of interactivity for students.

- Use the experience of this minimalist online presence as a basis for professional development of academic staff so they can author materials via web forms and wizards, thus enabling them to focus on content rather than technical detail. These forms and wizards allow interactive texts, discussions and quizzes to be authored. Subject development can then focus on the institution's strategy rather than the particular technical skills of groups of staff.

- Bring about the development of more sophisticated learning resources and interactive teaching strategies within specific courses that can be linked into this common framework. The authoring software recommended for this development is MS FrontPage due to its integration with other software used on staff desktops.

- Use the success of extended online delivery of teaching and learning in specific courses as exemplars of good practice and models for the involvement of a wider group of academic staff and courses. External developers need to either utilise the standard tools or link their materials directly into the UniSAnet framework.

- Integrate over time (1) online forms of student support (e.g., access to a range of library services) and (2) online administrative functions (enrolment and fees payment) with teaching and learning resources available through UniSAnet to provide students with comprehensive electronic access to the university and its courses.

- Ultimately, for a number of courses, provide online all of a student's engagement with the University.

It needs to be stressed that UniSAnet is a University-wide initiative. As such, standards, which meet the criteria listed above, prevail that are consonant with the University's mission and reputation. While it is intended to provide opportunities for staff and courses to be represented online, this is within the context 
of University ownership of the online presence, both in terms of its presentational standards and existing delegations which control information relating to the institution and its programs. Thus the templates and professional guidance linked to the web forms and wizards are designed with both quality standards and the institution's teaching and learning strategy clearly implemented [14].

The UniSAnet strategy is to be reviewed on an annual basis, and in the case of the first year of operation, by an external consultant.

Within this structure, two crucial dimensions must be served: the fundamental role of professional development, and within that, the process of personal involvement of faculty to conceptualise online delivery.

\section{A. The Role of Professional Development}

In considering the role of professional development in Universities, Bradley notes:

“...the staff developer needs to understand the strategic goals of the institution, indeed be part of the development of these goals, and be able to engage in strategic application of their skills so that their impact is not marginalised or limited by individual 'consultative' action. Achieving this is not easy as it means reappraising roles of both staff developers and of others within institutions" [15].

So staff development in online delivery from this strategic perspective is not about supporting individuals' whims or interests, but focuses on institutional goals and plays a key role in shaping those goals. Within this role the staff developer needs to assist the individual academic to determine the level of engagement with online delivery.

\section{B. Level of Involvement of Academic Staff}

The level of engagement with online delivery is a decision for individual academic units within the university. The purpose of moving to an online teaching and learning environment is to afford different opportunities for teaching methodologies across the university. UniSAnet affords opportunities for academics to make a series of decisions about what the extent and role of the online dimension of their teaching programs will be. These decisions are made in concert with the university's commitment to student-centred and flexible learning, to inclusivity and diversity within the curriculum, to information literacy and engagement with communications technologies, and to internationalisation of and increased access to university courses [11].

King [16] has conceptualised this as a three tiered process:

- Supplementary suggests that the information, learning experiences or other services provided on line are also available in another form for students or are not core components of the program. The function of the online dimension is to provide choice in the way students access learning or to provide opportunities for extra experience.

- Complementary suggests that the material provided online adds to other methods of delivery and course components (e.g., face-to-face teaching) but that the online elements are integral to the course and there is no choice in how or whether they are to be accessed. The function here is to provide learning experiences that are enhanced by the media used to access them.

- Comprehensive replacement suggests that the online dimension has come to replace earlier forms of delivery. It indicates that the primary learning context is online but there would be scope for other directed learning experiences that were not computer mediated, e.g. texts, practical or laboratory work. The function here is to provide a comprehensive electronic learning environment for the subject concerned. 
Decisions about the level of commitment to online provision can be taken in relation to each of the total range of components which make up the student's experience of the subject, e.g., subject information, the teaching materials, a range of strategies for self-management of the learning program, assessment, additional learning resources, communications, support links such as the library and student service centres, and course administration.

\section{RETURNING TO THE CRITERIA}

The UniSAnet development addresses the system, producer and user issues.

\section{A. The UniSAnet System}

The UniSAnet online delivery system addresses the needs of the entire University by supporting all staff and students in accessing all subjects and courses online. The use of corporate databases for the storage and manipulation of all course-related information is an example of an open system that allows users to access data for a range of purposes not originally envisaged in their initial design. The development of the University's new student record system will interface directly with UniSAnet allowing a student's relationship with the University to be conducted entirely online.

The UniSAnet development exemplifies interoperability, followed by extensibility and finally functionality. Corporate databases are used to store information on all subjects within the university to be displayed via the browser and this can be achieved for every staff member and every student, individually authenticated. Sacrifices made in the area of functionality include the limited use of audio and video, however these can be integrated in a seamless way for priority developments via linkage to one-off developments.

Security issues are dealt with as staff and students are authenticated via the University-wide Windows NT accounts. This means that each student or member of staff needs only one username and password for all their electronic communications with the University. Students are provided access to materials needed for subjects in which they are enrolled via an automated process instigated from their enrolment.

\section{B. The UniSAnet Producers}

UniSAnet builds upon the university's processes for the identification of, and support for subject developers. The university has a coordinated planning process for all of its operations which include annual plans devised by its academic divisions as a result of their strategic considerations and the university's capacity to develop materials, in consultation with professional development and technical staff from the university's Flexible Learning Centre. Staff are identified and supported in their involvement in online delivery in these plans and given professional and technical support as identified in these plans.

In order to support the production of extensible and interoperable system components for UniSAnet, a team of information technology specialists has been established that is dedicated to working on UniSAnet within the university's Flexible Learning Centre which provides professional and technical support to academics. Library support is linked into the templates developed, so this can appear automatically for all materials. Products and services of external providers are rigorously tested before use. Access to corporate systems and information needed for the development of UniSAnet is coordinated between the Flexible Learning Centre and the University's Information Technology Services unit, which collaborates closely in the development of UniSAnet.

Standard tools agreed to for building UniSAnet are:

- MS FrontPage for HTML authoring 
- Oracle RDMS and MS SQL server for database development

- MS Active Server Page technology via ODBC for the linkage of databases to web pages

- MS Exchange for messaging (every staff member and student has an Exchange account, accessed via Outlook or a web interface)

- MS FrontPage threaded discussions and Exchange public folders via Outlook forms for interactivity

- any version 3 browser can be used for student web browsing and any version 4 browser can be used by staff for authoring materials

- MS Internet Information Server for internet server software

\section{The UniSAnet Users}

The University has contracted a preferred Internet Service Provider that provides internet and intranet access to staff and students at reduced rates and provides its own dialup facility for some staff and postgraduate students. Intranet sites are of two types - either password protected, or accessible to all students within the intranet, but inaccessible to the outside world.

Students can access all materials with a standard version 3 web browser with no additional plug-ins. Interactive materials will be asynchronous for reasons of bandwidth, and pedagogy, since synchronous interactivity is problematic in that it removes a critical flexibility - that of being able to access interactions at any time.

Permission to write static teaching materials is granted to staff responsible for the subject(s) and for interactive sites is limited to staff and students directly engaged in a subject, or can be more widely accessible if required. Access to read those materials with an intellectual property component is limited to the students and staff engaged in a particular subject. In this way staff and students are provided access to the materials they need - but only those.

As materials are authored via forms and wizards on a standard web interface, the staff development required can focus on pedagogical decisions, as the technical skills are limited to typing, cutting and pasting, and the use of a web browser. Student learning required to enable access learning experiences is minimal, as the interface is a standard browser. The University also provides free orientation training to the University's online environment, and produces a range of support resources in print and electronic form.

Maintenance of software and hardware is the responsibility of the UniSAnet team while academics maintain the content of the learning materials for which they are responsible. The cognitive load caused by switching from one environment to another is greatly reduced as all materials use a standard set of templates that are consistent across all subjects.

All online materials are user tested before release to users.

\section{CONCLUSION}

The online environment presents universities with a range of choices relating to technical specifications, resource commitments, staff expertise, quality control and efficiency, to name a few. The competitive environment in which universities find themselves means that these decisions could be critical to an institution's survival. Choices need to be made about the competitive advantage to be gained in a global environment [17]. These choices need to be taken in a rapid and comprehensive manner if they are to be effective. The UniSAnet initiative is an example of a University-wide, comprehensive approach to the challenge of integrating IT into teaching and learning that enables rapid and flexible delivery strategies to 
be invoked. Universities ignore the threats and opportunities that the burgeoning online learning environment provides at their peril.

\section{REFERENCES}

1. DeLong, S.E., The Shroud of Lecturing, First Monday 2, 5, 1997. http://www.firstmonday.dk/issues/issue2 5/delong/index.html

2. Margolis, M., Brave New Universities, First Monday 3, 5, 1998. http://www.firstmonday.dk/issues/issue3_5/margolis/index.html

3. Noble, D.F., Digital Diploma Mills: The Automation of Higher Education, First Monday, 3, 1, 1998. http://www.firstmonday.dk/issues/issue3_1/noble/index.html

4. Turoff, M., Alternative Futures for Distance Learning: The Force and the Darkside, Keynote presentation at the UNESCO / Open University International Colloquium, April, 1997. http://eies.njit.edu/Papers/darkaln.html

5. Bates, A.W., Technology, Open Learning and Distance Education, London, Routledge, 1995.

6. Bates, A.W., Restructuring the University for Technological Change, Paper delivered at Carnegie Foundation for the Advancement of Teaching - What Kind of University?, London, June, 1997.

7. Goldman, Steven L, Goldman, Roger $\mathbf{N}$ and Nagel, Kenneth, Agile Competitors and Virtual Organizations : Strategies for Enriching the Customer, New York: Van Nostrand Reinhold, 1995.

8. Yetton, Philip, et al, Managing the Introduction of Technology in the Delivery and Administration of Higher Education, Evaluations and Investigations Program, Higher Education Division, Canberra: AGPS, 1997.

9. Hicks, M and George, R., A Strategic Perspective on Approaches to Student Learning Support at the University of South Australia, Paper delivered at the HERDSA conference, Aukland, July, 1998.

10. Evans, T., Globalisation, post-Fordism and open and distance education, Distance Education, 16, 2, 1995.

11. Evans, T.D. and Nation, D.E. Theorising Open and Distance Education. in Key Issues in Open Learning, ed. A.W. Tait, Longman, London, 1993.

12. King, B., (1993) Open learning in Australia: Government intervention and institutional response, Open Learning, 8(3) 1993.

13. Giddens, A. (1991) The Consequences of Modernity, Polity Press, Cambridge.

14. Nunan, T., Interrogating the concept of flexibility, in Jakupec, V. and Garrick, J. eds., Flexible Learning, the Workplace and HRD: Putting Theory to Practice, London, Routledge, forthcoming.

15. Bradley, D., Staff Developer as Strategist, Paper delivered at the AHED Forum, New Millenium, Four Winds, AHED of Change, Adelaide, July, 1997.

16. King, B., Establishing UniSAnet: the On-line Environment of the University of South Australia, Paper presented to the Information Technology Advisory Committee, University of South Australia, June, 1998.

17. Marginson, S., Nation-building Universities in a Global Environment: The Choices Before Us' Public Lecture Series - The Role of Universities in Australia in 2010, University of South Australia, September, 1998. http://www.unisa.edu.au/NEWSINFO/lecture/Marginson_lecture.htm 